University of Montana

ScholarWorks at University of Montana

Graduate Student Theses, Dissertations, \&

Professional Papers

1970

\title{
Effect of task complexity on awareness and performance in attitude conditioning
}

Michael Lee Brown

The University of Montana

Follow this and additional works at: https://scholarworks.umt.edu/etd

Let us know how access to this document benefits you.

\section{Recommended Citation}

Brown, Michael Lee, "Effect of task complexity on awareness and performance in attitude conditioning" (1970). Graduate Student Theses, Dissertations, \& Professional Papers. 4919.

https://scholarworks.umt.edu/etd/4919

This Thesis is brought to you for free and open access by the Graduate School at ScholarWorks at University of Montana. It has been accepted for inclusion in Graduate Student Theses, Dissertations, \& Professional Papers by an authorized administrator of ScholarWorks at University of Montana. For more information, please contact

scholarworks@mso.umt.edu. 
THE EFFECT OF TASK COMPIEXITY ON AWARENESS AND

PETRORMLANCE IN ATTITUDE CONDITIONING

By

Michael L. Brown

B.A., College of Great Falls

Presented in partial fulfillment of the requirements for the degree of Master of Arts

UNIVERSTTY OF MONTANA

1970

Approved by:
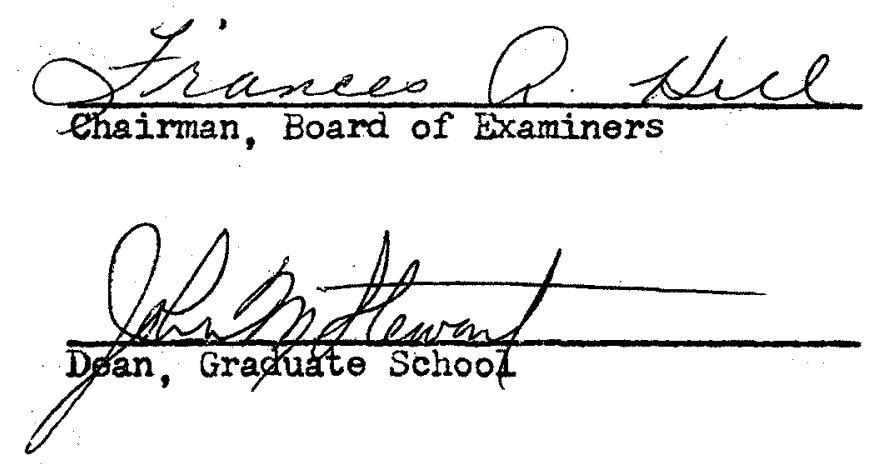
Date $2 \operatorname{coc} 14,1970$ 
153.15

38792 e 
UMI Number: EP40383

All rights reserved

INFORMATION TO ALL USERS

The quality of this reproduction is dependent upon the quality of the copy submitted.

In the unlikely event that the author did not send a complete manuscript and there are missing pages, these will be noted. Also, if material had to be removed, a note will indicate the deletion.

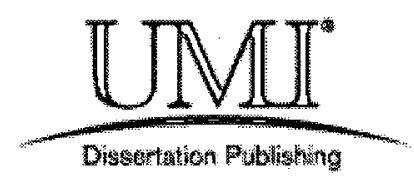

UMI EP40383

Published by ProQuest LLC (2014). Copyright in the Dissertation held by the Author.

Microform Edition (c) ProQuest LLC.

All rights reserved. This work is protected against unauthorized copying under Title 17, United States Code

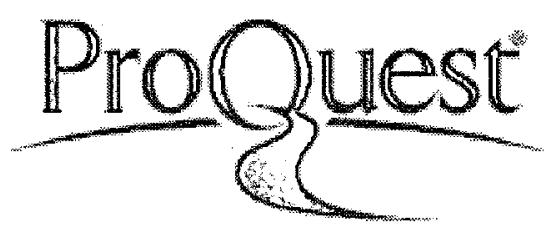

ProQuest LLC.

789 East Eisenhower Parkway

P.O. Box 1346

Ann Arbor, MI $48106-1346$ 


\section{ACKNOWLEDGMENTS}

The author wishes to express his sincere gratitude to the members of his thesis committee, Dr. Duane Hampton, Dr. Andrew Lee, and Dr. Odin Vick. Special thanks must go to Dr. Frances Hill, thesis committee chairman, whose vivacity, generosity, and scholarship sustained the author in many moments of doubt and constermation. 
TABLE OF CONTENTS

Page

ACKNOWLEDGMENTS ................... ii

LIST OF TABLES . . . . . . . . . . . . . . v v

Chapter

I. INTRODUCTION .................. 1

REVIEW OF THEORIES ............... 1

STATEMENT OF PROBIEM ............. 5

PILOT STUDY ..................... 6

FURTHER CONSIDERATIONS . . . . . . . . . 9

SUMMARY AND PREDICTIONS .......... 10

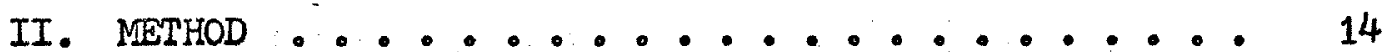

SUBJECTS ........................ 14

ATTITUDE QUESTIONNAIRES .......... 14

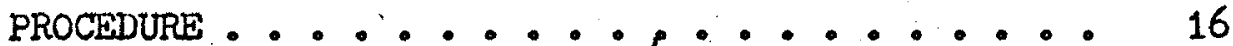

III. RESULTS .............. 18

MEASUREMENT OF AWARENESS .................. 18

RESPONSE ACQUISITION .................. 19

RESPONSE ACQUISITION AND AWARENESS . . . . . 22

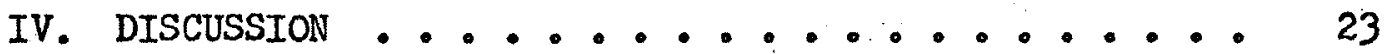

v. SUMMARY .................. 28 
APPENDIX I.................... 29

APPENDIX II ........................ 31

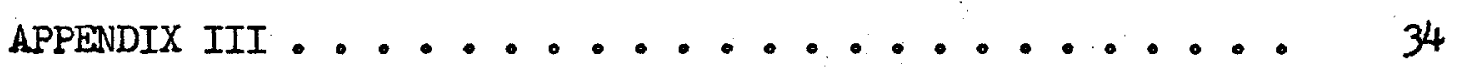

APPENDIX IV ............................. 37

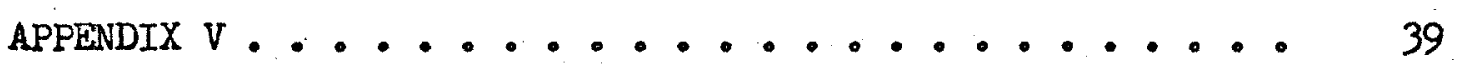

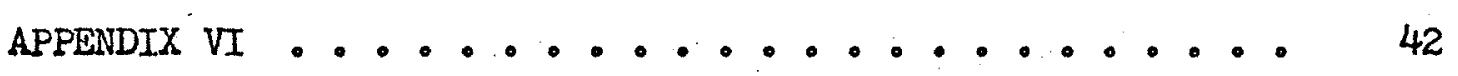

BIBLIOGRAPHY ..................... 45 
LIST OF TABLES

Table

Page

1. Number of Subjects Rated as Aware or Unaware in Each of Three Experimental Groups .........

2. Mean and Standard Deviations of the Number of Responses in the Direction of Reinforcement (Theoretical Responses or Responses Favorable Towards Pay TV) for All Groups ........ 20

3. Mean Number of Responses in the Direction of Reinforcement for Aware and Unaware Subjects in the Three Experimental Groups ......... 
CHAPTER I

INTRODUCTION

\section{Review of Theories}

The controversy about learning and awareness has been a popular topic in psychology for many years. The essence of the leaming-awareness controversy involves the question of whether awareness (generally defined as correct verbalization of responsereinforcement contingencies) is a necessary precondition of learnIng or whether it simply occurs as a result of learning.

Psychologists who uphold a nonmediational, stimulus-response model of learning have asserted that awareness occurs as a result of learning (Greenspoon, 1967; Thorndike, 1933; Verplanck, 1962). According to this theoretical position, reinforcing consequences act directly and automatically to strengthen stimulus-response connections. If awareness does occur, it is an after-effect of this direct action. Counterposed to this behavioristic interpretation of the relationship between learning and awareness is the position propounded by the cognitive theorists. They maintain that awareness is a necessary precondition of learning. The major empirical and theoretical support for this view has come from Spielberger and his associates (Spielberger, Berger, \& Howard, 1963; Spielberger \& De Nike, 
1962; Spielberger, Levin, \& Shepard, 1962; Spielberger, Ratliff, \& Bernstein, 1966; Spielberger, Southard, \& Hodges, 1966).

A third major theoretical position has been proposed which assumes that awareness is both a consequence and a condition of behavior change (Bandura, 1969; Farber, 1963; Postman \& Sassenrath, 1961.) Bandura has termed this particular formulation the "reciprocal interaction theory." According to this theory, a certain amount of learning can take place in an automatic, non-mediational fashion. However, during the acquisition process, subjects (Ss) not only make overt responses, but also formulate hypotheses about the responses required to produce reinforcement. Once a correct hypothesis has been formed, dramatic and sudden performance gains often ensue. The learning and awareness controversy has not been settled. A review of the literature dealing with verbal operants, problem solving and attitudes yields empirical data which would seom to support any one of three theories that have been presented. In light of these contradictory results, a number of psychologists have voiced the opinion that the learning and awareness issue may be meaningless, or, at least for the present, insoluble (Eriksen, 1962; Greenspoon, 1967; Kimble, 1962). None of these psychologists would deny, however, that awareness can have a marked facilitative effect upon performance. Bandura (1969) has presented some suggestive hypotheses about several variables that may have been responsible for the divergent results that pervade the literature. He maintains that the disparate 
findings may, in part be a consequence of the principle governing the administration of reinforcement and the response restrictions imposed by the nature of the learning task. He points out that studies in which awareness is concurrent with dramatic performance gains generally employ fairly simple tasks that require Ss to select from one of a small number of relatively unambiguous response classes. These response classes are readily available within s's repertoire $\left(1_{0} \theta_{0}\right.$, S may more adequately be described as choosing from response alternatives already in his repertoire rather than as acquiring new responses). An example of, a task of this sort would be the sentence construction task devised by Taffel (1955). In this task, Ss are instructed to construct a short sentence by choosing one of a small number of pronouns, adjectives, verbs or nouns printed on cards. Commonly the experimenter (E) reinforces the emission of a predetermined response class (e.g.; human nouns, intensely hostile adjectives) by saying "good."

Using a task such as this is likely to produce awareness and learning as a one-trial event rather than as an incremental process. While a cognitive theorist might consider a one-trial event as evidence for awareness being a necessary precondition of behavior change, such an assertion, from the writer's point of view, seems too extravagant. The experimental unit of a leaming trial is, after all, just a convenient way of designating what is probably a rather complex process of some duration. If two performances are assessed at the 
termination of a learning trial--verbalized awareness and behavior change--all that one can strictly and objectively state is that both have occurred during that interval of time. To say that awareness is a necessary precondition of learning seems premature. The reciprocal interaction theory as interpreted by Bandura simply states that given a certain context (a relatively simple verbal operant task) awareness and behavior change are likely to occur "together" rather than "apart." The theoretical issue of whether awareness must mediate behavior change is left open.

If awareness and behavior change are likely to occur together in a simple verbal operant task like the one devised by Taffel, the most probable outcome that a reciprocal interaction theory would predict is the same outcome that a cognitive theory might predict, though for different reasons--performance gains only by aware Ss. Spielberger's repeated findings of performance gains only for aware Ss in the Taffel task seems to lend support to Bandura's contentions about task complexity.

There also seems to be some supporting evidence for Bandura's contention that a more difficult or complex task is likely to produce performance gains for Ss that are unaware. Philbrick and Postman (1955) obtained results in line with this prediction using a task in which Ss were required to respond with a number between 2 and 9 when they were presented a stimulus word varying in length from two to ten letters. The reinforcement contingency which if learned would 
produce $100 \%$ reinforcement was: choose a number which is equal to the number of letters in the stimulus word minus one, e.g., test-3, telephone-8, and so forth. Sassenrath (1962) also found performance gains for unaware Ss using a task similar to the one used by Philbrick and Postman. Thus in comparison to the procedure developed by Taffel, these tasks appear to be relatively complex as a function of several variables $(\theta . g$. , the complexity of the principle governing reinforcement and the number of possible response alternatives).

\section{Statement of Problem}

Although Bandura's hypotheses concerning the degree of task complexity originated in an attempt to explicate divergent findings in the area of verbal operants, problem solving and the like, it appeared that the analysis could be extrapolated to clarify certain puzzling results in the area of attitude conditioning. A case in point is the finding of attitude conditioning of uneware Ss (Hildum \& Brown, 1956; Insko \& Butzine, 1967; Insko \& Nelson, 1969)。 Rather than considering the possibility that such findings might be a result of task complexity, these experimenters have explained their results by contending that Ss perceive and interact with attitude material in a fashion fundamentally different from that in which they deal with nonnormative material. For example, Hildum and Brown maintain that the attitude situation "makes sense" as presented. Consequently, 
Ss do not attend so closely to $\underline{E}^{\prime}$ s reinforcing statements (e.g., "good"). Insko contends that Ss automatically defer to the attitude $E$ is reinforcing with little attention to what is going on. Insko speculates that people have learned to defer rather than oppose other's opinions and attitudes in order to avoid the aversive consequences (social friction) that might otherwise ensue.

The purpose of the present study was to consider the findings of the attitude conditioning situation from the point of view of possible complexity involved. It seemed reasonable that Bandura's notions might apply in this situation and that, to the extent this was the case, the postulation of processes peculiar to the attitude situation was unnecessary.

\section{Pilot Study}

One possible source of complexity that appeared to be operating in the attitude conditioning situation involved the availability and ambiguity of response classes. The work of Insko $(1967,1969)$ is a case in point. Insko's attitude questionnaire (See Appendix I) was designed to deal with an issue that seemed from the writer's point of view, somewhat foreign to a number of people--the issue of Free TV versus Pay TV. Thus it seemed reasonable to suppose that the attitudes represented by the items might not be readily available in S's repertoire. In addition, inspection of the items yielded a feeling of great ambiguity; $i_{.} \theta_{.}$, the writer often questioned whether 
or not a particular item would be perceived by $\underline{\mathrm{S}}$ as "pro" or "con" Pay TV. Accordingly, a pilot study was designed to assess these notions. In addition a second attitude questionnaire was devised by the writer (hereafter referred to as the Theoretical Attitude Questionnaire; see Appendix II) and included in the pilot work in an attempt to overcome the complexity thought to be present in Insko's questionnaire: The items in the Theoretical Attitude Questionnaire were derived from or suggested by the study of values (Allport, Vermon, \& Iindzey, 1960). They were written in such a way as to attempt to avoid ambiguity and they dealt with an issue which seemed more widely shared. Both questionnaires contained twelve items.

Each $\underline{S}$ in one group of $15 \underline{S s}$ was presented the items included in Insko's attitude questionnaire, half of which are meant to be favorable towards Pay TV and half of which are meant to be unfavorable. Each attitude item was typed on a $3 \times 5$ inch card and arranged randomly. in a deck. The $S$ was given the deck and was instructed that it consisted of 12 attitude statements which could be sorted into two different and distinct categories. The $\underline{S}$ was also told not to separate the attitude statements on the basis of how he personally felt about the items. The $\underline{E}$ recorded how long it took each $\underline{S}$ to complete the sorting task and how many errors in placement occurred.

Each $\underline{S}$ in the second group of 15 Ss was given a deck of the twelve items from the Theoretical Attitude Questionnaire. Six of these items were favorable towards a theoretical interest and six 
were unfavorable towards a theoretical interest. The Ss in this group received the same instructions as the group that received Insko's questionnaire.

The mean time for placement in the group that received Insko's questionnaire was $114.5 \mathrm{sec}$; the mean time for placement in the group that received the Theoretical Attitude Questionnaire was 78.5 sec.. The total number of incorrect placements in the group that received Insko's items was 24; the total number of errors in place. ment for the group that received the Theoretical items was 11. At the termination of the task each $\underline{S}$ was asked on what basis he had made his sorting. Only three Ss in the group that received the Theoretical Attitude Questionnaire showed any difficulty in identifying the categories. These Ss gave what amounts to "correlated" hypotheses; e.g., one $\underline{S}$ replied, "One had something to do with beauty and creating things and the other was about science and stuff like that."

Seven Ss who received Insko's items seemed to have some difficulty in identifying the basis of their sorting. One of these Ss sorted the cards into one stack that contained items 6 and 10 and another stack that contained all of the other items. When asked the basis of his sorting, $\underline{S}$ replied that he had sorted the cards into one stack that dealt with commercials and one stack that dealt with entertainment. 
Since the group that was presented the items from Insko's attitude questionnaire had a greater mean time to complete the card sorting task, made more errors in placement, and appeared to have greater difficulty in identifying the "correct" response classes, it seemed reasonable to conclude that the Theoretical attitude task was less complex. It also seemed reasonable to conclude that this was due, at least in part, to availability and lack of ambiguity of response classes in the Theoretical Attitude Questionnaire, as compared with Insko's questionnaire.

\section{Further Considerations}

A second source of complexity that seemed likely to be operating in the attitude conditioning situation involved the nature of the response alternatives present on any given trial. Hildum and Brown, as well as Insko and his associates, have consistently employed a task (e.g., Insko's questionnaire) in which either a favorable or an unfavorable item is present on each trial, but not both. It may be that the opportunity to compare stimuli simultaneously can be a distinct help in the learning of relationships among stimuli (Deese \& Hulse, 1967). Although such a statement is most directly related to the phenomenon of transposition, it seems relevant to the present issue. The attainment of awareness may be viewed as the learning of a relationship between a reinforcing stimulus and several other classes of stimuli. Perhaps the lack of explicit presentation of 
both favorable and unfavorable classes of responses on each trial militates against a one-trial learning and awareness event. In point of fact, in the Taffel task, where one-trial learning and awareness has been found to occur, both the reinforced and nonreinforced classes are explicitly present on each trial of the experiment.

A test of this hypothesis would require a comparison of the

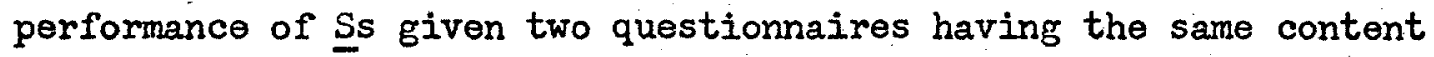
and equated in terms of availability and lack of ambiguity but differing in terms of the number of response classes present on each trial. In order to do this, E devised a questionnaire dealing with S's theoretical attitudes which was as comparable as seemed possible to the Theoretical Attitude Questionnaire, except that both favorable and unfavorable classes of responses were present on each trial (see Appendix III). This questionnaire will hereafter be referred to as the Theoretical-Aesthetic Attitude Questionnaire.

\section{Summary and Predictions}

In summary, it was hypothesized that Ss do not percoive and interact with normative material in a fashion fundamentally different from the way in which they deal with nonnormative material. It was felt that the reported findings of performance gains for unaware Ss in several attitude conditioning experiments was a consequence of 
the complexity of the task rather than, for example, some inaccessible, automatic deference response. Three potential sources of complexity present in the attitude questionnaires used by the experimenters who have reported significant performance gains for unaware Ss were considered. These were: availability of response classes, comparative difficulty of identifying an attitude item as an instance of an attitude class (ambiguity), and explicit presentation of reinforced and nonreinforced response classes on each trial of an experiment. An experiment was designed to test the validity of these ideas. Two attitude questionnaires were developed in such a way as to deal with each of the three hypothesized sources of complexity. One of the questionnaires (the Theoretical Attitude Questionnaire) was designed to be simpler by virtue of the greater availability of the response classes involved and the lesser ambiguity of the items. Pilot work suggested the attempt had been successful. The other questionnaire (the Theoretical-Aesthetic Attitude Questionnaire) was designed to be comparable to the Theoretical Questionnaire in terms of these two sources of complexity, but to introduce a further simplification--the explicit presence of both favorable and unfavorable responses on each trial of the experiment. An attitude conditioning experiment was then conducted, the major purpose of which was to compare the performances on each of the two newly-devised questionnaires. and the more traditional questionnaire employed by Insko. 
Based upon the verbal conditioning literature which has dealt with nonnormative material, the following predictions were made:

(1) There should be fewer aware Ss in a group that receives Insko's attitude questionnaire than in a group that receives the Theoretical Attitude Questionnaire. This first prediction follows from the contention that the Theoretical Attitude Questionnaire is relatively less complex when compared to Insko's questionnaire, and the general findings in the literature that the easier or less complex the task is, the greater will be the number of aware $\underline{\text { Ss. }}$

(2) In a relatively complex task such as Insko's the possibility exists that some Ss will show significant performance gains but be unaware of the experimental reinforcement contingencies. In a relatively easy attitude task such as the Theoretical Attitude task the possibility of performance gains for unaware Ss should be greatly reduced. It is more likely that performance gains should be limited to only aware Ss. This prediction is derived from Bandura's notion that a more complex or difficult task is likely to produce performance gains by unaware Ss, but a fairly simple task is likely to produce a one-trial learning and awareness process, and thus, performance gains only for aware $\underline{\text { Ss. }}$

(3) The mean number of responses favorable to the attitude class $\mathrm{E}$ is reinforcing should be greater for a group that receives the Theoretical Attitude Questionnaire than for a group that receives Insko's questionnaire. This prediction follows from the contention that there will be more aware Ss in the group given the Theoretical Attitude Questionnaire than in a group given Insko's questionnaire, and the general findings in the literature that awareness is a sufficient condition for sudden and dramatic performance gains.

(4) There should be more aware Ss in a group that receives the Theoretical-Aesthetic Attitude Questionnaire than in a group that receives either the Theoretical Attitude Questionnaire or Insko's questionnaire. This prediction follows from the contention that explicit presentation 
of both reinforced and nonreinforced response classes on each trial of an experiment simplifies a task even more than if only the two sources of complexity (unavailability and ambiguity) are removed as in the Theoretical Attitude Questionnaire. Since all sources of hypothesized complexity are still potentially present in Insko's questionnaire, it follows that there should be more aware Ss in the Theoretical-Aesthetic group where all sources of hypothesized complexity have been removed.

(5) The mean number of responses favorable to the attitude class $E$ is reinforcing should be greater in a group that receives the Theoretical-Aesthetic Questionnaire than in a group that receives either Insko's questionnaire or the Theoretical Questionnaire. Again, this prediction follows from the notion that a simpler task produces more aware Ss. If there are more aware Ss in one group than in another, assuming that the groups are of equal size, and awareness is correlated with dramatic performance gains, then the mean performance score for the group containing the most aware Ss should be greater than the mean performance score for the group containing fewer aware Ss. 
CHAPTER II

METHOD

Subjects

The Ss were 120 undergraduate students enrolled in the introductory psychology class at the University of Montana. These students were participating in the experiment in order to complete a course requirement. Each $\underline{S}$ was randomly assigned to one of six groups. There were 20 Ss in each group.

\section{Attitude Questionnaires}

There were three attitude questionnaires. The content of two of these questionnaires were suggested by the study of values (Allport, Vernon, \& Iindzey, 1960). The Study of Values attempts to measure the relative prominence of six interests or motives in personality: theoretical, economic, aesthetic, social, political, and religious. In general, this test is organized so that a preference for one interest is paired with a preference for another interest and the individual taking the test assigns relative weights $(3,2,1,0)$ to one or both of the interests. In this study only items similar in content to two of the six value classes were used--the theoretical and the aesthetic. Also, rather than assign relative weights to the value 
classes, Ss were instructed either to state a preference for one or the other of the value classes (Theoretical-Aesthetic Attitude Questionnaire) or to agree or disagree with a statement which expressed a positive evaluation of one of the value classes (Theoretical Attitude Questionnaire). Insko's pay TV--free TV questionnaire was the third questionnaire used.

Each of the three attitude questionnaires was administered to 40 Ss; 20 Ss received the experimental reinforcement treatment and 20 Ss served as a control group. The experimental Ss who received Insko's questionnaire were reinforced for expressing either agreement with a statement favoring pay TV or disagreement with a statement favoring free TV. The experimental Ss who received the Theoretical Attitude Questionnaire were reinforced for either agreeing with statements expressing a theoretical interest or disagreeing with a statement expressing an aesthetic interest. The experimental Ss who received the Theoretical-Aesthetic Attitude Questionnaire were reinforced when they indicated that the theoretical alternative was their preference.

All of the attitude statements were typed on white $3 \times 5$ inch cards. The order of presentation of the twelve statements in each of the three attitude questionnaires was randomized. The attitude statements were presented through an aperture on a black screen in order to eliminate visual contact with the Ss. The exposure time of the statements varied as a function of the type and complexity of the 
statements. There was a five second intertrial period between the presentation of successive statements.

\section{Procedure}

When each $\underline{S}$ arrived, $\underline{E}$ told him that the experiment dealt with people's attitudes about either pay TV or science, depending upon the group to which he was assigned. The $\underline{E}$ explained that $\underline{S}$ would be administered a questionnaire consisting of twelve statements typed on cards, and that these cards would be presented through a slot in the black screen. Each $\underline{S}$ was instructed to read each statement aloud. When an experimental $\underline{S}$ responded favorably toward either Pay TV or a theoretical interest, E said "good" in a flat, unemotional tone. Nothing was said when $\underline{S}$ responded favorably toward free TV or an aesthetic interest. Control Ss simply read the statements, and never received reinforcement.

After each experimental $\underline{S}$ had been administered one of the three questionnaires, E asked him the questions (somewhat modified for the purposes of this experiment) included in Dulany's awareness questionnaire (see Appendix IV). Each $\underline{S}$ was then informed about the nature of the experiment and requested not to discuss the experiment with anyone who might participate in it at some future time.

Appendix V presents the exact instructions given $\underline{S}$ that received each of the three attitude questionnaires. Also, after 
the experiment was underway $\underline{E}$ found it necessary to create some additional instructions for the group that received Insko's questionnaire (see Appendix VI for these instructions and the reasons that necessitated their creation). 
CHAPTER III

RESULTS

Measurement of Awareness

The criteria used to classify Ss as aware or unaware were taken from Dulany (1961) and were as follows:

(1) Aware--the subject reports the significance of the contingent stimulus. The subject signifies that the preceding response was correct or what $E$ wanted or would agree with. The contingent stimulus is described as having some selective reinforcement or informative value, not as a general encouragement to continue.

(2) Unaware--the subject reports one of several things: an incorrect or incompatible response class, the occurrence but neither the significance nor the distribution of the contingent stimulus, or does not report the occurrence of the contingent stimulus.

Table 1 presents the number of aware and unaware Ss in each of the experimental groups. It was hypothesized that there would be more aware Ss in a task where both reinforced and nonreinforced response classes were explicitly present on each trial of the experiment than there would be in a task where only one of the response classes was present on each trial. The former situation is represented in Table 1 by the Theoretical-Aesthetic task while the latter situation is represented by the Theoretical task. A Chi Square test was performed 
in order to ascertain whether being in one group or the other had an effect on the proportion of aware $\underline{S}$ in these groups. This test was significant $\left(x^{2}=3.95, p<.05\right)$. A task in which both response classes are present on each trial of the experiment does produce more aware Ss.

It was also hypothesized that there would be more aware $\underline{S}$ in a group given the Theoretical task than in a group given Insko's task. Inspection of Table 1 indicates that this prediction was not confirmed.

\section{Table 1}

Number of Ss Rated as Aware or Unaware

in Each of Three Experimental Groups

\begin{tabular}{lll}
\hline Aware & Unaware & \\
10 & 10 & Insko's Attitude Task \\
10 & 10 & Theoretical Task \\
16 & 4 & Theoretical-Aesthetic Task \\
\hline
\end{tabular}

Response Acquisition

Table 2 presents the data relevant to treatment effects. It was hypothesized that there would be treatment effects for all experi- 
mental groups. Differences between the means of experimental and control groups were evaluated by $t$ tests between the means of independent samples. The difference between the control and experimental means for the Theoretical-Aesthetic group was significant $(t=2.49$, $\mathrm{df}=38, \mathrm{p}<.025)$. Reinforcing theoretical preferences with "good" did have the expected effect of increasing the emission of this response. The comparison of means for the control and experimental groups of the Theoretical task approached a conventional level of significance $(t=1.57, d f=38, p<.07)$. However, inspection of Table 3 where treatment means have been computed for both aware and unaware Ss in this group yields a more substantial treatment effect. A comparison of the mean of the aware Ss (unaware Ss excluded) with their appropriate controls was significant $(t=1.76, d f=28, p<.05)$.

\section{Table 2}

Mean and Standard Deviations of the Number of Responses in the Direction of Reinforcement (Theoretical Responses or Responses Favorable Towards Pay TV) For All Groups

\begin{tabular}{lll} 
Experimental & & Control \\
\cline { 1 - 2 } 5.5 & 5.3 & \\
$S D=2.09$ & $S D=3.31$ & Insko's Attitude Task \\
6.0 & 5.2 & \\
$S D=1.78$ & $S D=1.44$ & Theoretical Task \\
7.2 & 5.8 & \\
$S D=1.96$ & $S D=2.27$ & Theoretical-Aesthetic Task
\end{tabular}


This means that although aware Ss did give significantly more responses favoring a theoretical interest, this result was obscured by computing a treatment mean that included the scores of unaware Ss who did not give significantly more responses favoring a theoretical interest. This situation and the consequent computation of treatment effects based on the mean of only aware $\underline{S}$ is comon in the literature. It is easy to see that the obscuring of treatment effects by the presence of unaware Ss did not occur in the group that received the Theoretical-Aesthetic questionnaire since there are so few unaware $\underline{\text { Ss. }}$ The $t$ value for the comparison of means in the Insko attitude task was nonsignificant $(t<1)$.

Table 3

Mean Number of Responses in the Direction of Reinforcement for Aware and Unaware Ss in the Three Experimental Groups

Insko's Attitude Task

$\begin{array}{ll}\text { Aware } & 5.7 \\ \text { Unaware } & 5.3\end{array}$

Theoretical Task

$\begin{array}{ll}\text { Aware } & 6.2 \\ \text { Unaware } & 5.8\end{array}$

Theoretical-Aesthotic Task

Aware $\quad \mathbf{7 . 4 4}$

Unaware $\quad 6.25$


Response Acquisition and Awareness

It was hypothesized that only aware Ss would show any evidence of learning in the Theoretical-Aesthetic or Theoretical groups. The comparison of the mean of the aware Ss of the Theoretical-Aesthetic group with their appropriate controls was significant $(t=2.10$, $\mathrm{df}=28, p<.025)$. The comparison of means for unaware $\mathrm{Ss}$ and their appropriate controls was nonsignificant $(t<1)$. The comparison of means for aware $\underline{S s}$ and their appropriate controls in the Theoretical group was significant as already reported. The comparison of the mean of the unaware Ss with their appropriate controls was nonsignificant $(t<1)$. Neither the aware nor unaware Ss that received the attitude questionnaire devised by Insko showed any significant learning. 


\section{CHAPTER IV}

\section{DISCUSSION}

In general the results for the groups that received the attitude questionnaires devised by $\underline{\mathrm{E}}$ were consistent with predicted outcomes. The Theoretical-Aesthetic treatment which was most similar to the verbal operant task devised by Taffel (response class availability and explicit presentation of both reinforced and nonreinforced classes of responses on each trial of the experiment) yielded significant reinforcement effects and a large proportion of aware Ss. Also consonant with the repeated findings of Spielberger and his associates, there was no evidence for learning by Ss who could not verbalize the experimental reinforcement contingencies.

The group that received the Theoretical treatment where only one class of responses was explicitly present on each trial of the experiment also performed as predicted--nearly significant treatment effects, significantly fewer aware Ss than the group that received the Theoretical-Aesthetic treatment, and no evidence of learning by unaware Ss. This task is similar to the relatively simple Taffel Task in that the response classes are readily available within the Ss repertoire and is different since only the reinforced or the nonreinforced class of responses is explicitly present on each trial. The lack of explicit presentation of both classes of responses seems 
to have the effect of introducing some degree of task complexity, thus producing fewer aware Ss and somewhat less substantial treatment effects.

Although it was originally hypothesized that the magnitude of difference between the experimental and control groups of the TheoreticalAesthetic group would be significantly greater than the magnitude of difference between experimental and control groups of the Theoretical treatment group thus indicating, along with the proportion of aware Ss, a greater degree of task simplicity, the disparate way in which the control Ss in these two groups responded does not allow one to make any straightforward comparisons. While it was assumed that the two questionnaires would be equivalent (Ss would give the same number of pro-theoretical responses to each questionnaire) there is enough of a mean difference $(.6)$ to suggest that the questionnaires were not equivalent in this respect. If they are not equivalent, then different individuals are confounded with different tests and no rigorous comparison can be performed. The magnitude of difference was, however, in the predicted direction (1.4 for the Theoretical-Aesthetic group and .8 for the Theoretical group).

In summary, an attitude task which was designed to be similar to the nonnormative verbal operant Taffel task in terms of availability of response classes and/or explicit presentation of response classes yields results which are highly consonant with results obtained when 
using the verbal operant task. When sources of complexity are eliminated from normative tasks, Ss do not perceive and interact with them in a fundamentally different fashion than the way they deal with nonnormative tasks. Certainly these results also stand in stark contrast to the results that would be expected if one entertained a theory such as Insko's that postulates "automatic unconscious deference responses." The Ss may have "deferred" but in as much as they did, they were aware of what they were doing.

The hypotheses that were entertained regarding Insko's Free TV--Pay TV attitude task were not confirmed--there were no treatment effects and no learning by unaware Ss. Although this summarizes the results for the Insko group, it does not express the frustration and difficulty $E$ encountered in trying to administer and to interpret the results of the Insko questionnaire. The $E$ found it necessary to introduce some additional instructions in order to break up what he interpreted as a good-bad evaluative set that led to a lack of response variability (see Appendix VI).

The introjection of these remarks did seem to break up the good-bad evaluative set. This procedure did have the effect, however, of rendering inconclusive several of the hypotheses entertained with regard to Insko's task. Two of the three features of Insko's attitude questionnaire that $\underline{\mathrm{E}}$ thought may have introduced task complexity-response class availability and ability to correctly identify a 
particular response as a member of a class of responses--may have been in part eliminated by these added instructions. This may have been instrumental in increasing the number of aware $\underline{S}$ in the Insko group; indeed, the number of aware Ss in this group was equal to the

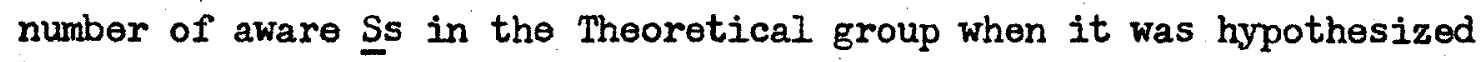
that there would be less. It is conceivable that the only source of task complexity that may have been untampered with was the lack of explicit presentation of both reinforced and nonreinforced classes of responses on each trial. Although the foregoing speculation might account for the number of aware $\underline{S}$, it does not account for the nonsignificant treatment effects for the Insko group. If the Insko questionnaire was completely equivalent to the Theoretical task devised by $\underline{E}$, one would expect significant treatment effects also. One possible explanation for this disparity might be in terms of "demand characteristics." Students enrolled in an introductory psychology course and participating in an experiment in which theoretical (scientific) preferences were being reinforced may have been more motivated to "play the game." The $\underline{S} \mathbf{s}$ in the Insko group, perceiving less connection between the content of the items and the context of the laboratory may have been less inclined to cooperate. The inability to replicate the "Insko Effect" renders untested, at least for this experiment, Bandura!s hypothesis that some learning may occur for $\underline{S}$ unaware of the experimental contingencies in a 
complex task. However, in light of the findings for the two attitude questionnaires devised by the writer, any assertion that individuals perceive and interact with normative material differently from the way in which they deal with nonnormative material must be seriously questioned. 


\section{CHAPTER V}

SUMMARY

The purpose of the present study was to investigate the contention made by Insko and others that people perceive and interact with normative material in a fashion that is fundamentally different from the way in which they deal with nonnormative material. It was maintained that the reported finding of attitude conditioning of unaware Ss was a result of task complexity rather than some intrinsic difference between normative tasks (attitudes) and nonnormative tasks (verbal operants, problem solving, өtc.).

Novel attitude questionnaires were constructed which the writer believed would be free of potential sources of task complexity.

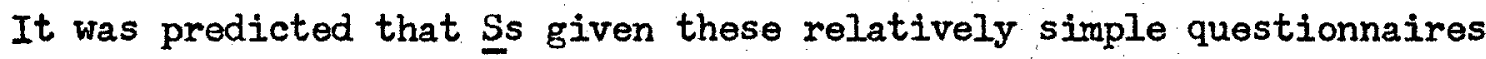
in an attitude conditioning experiment would not show any performance gains unless they were aware. This prediction was confirmed. The results of this experiment may indicate that it is not possible to "influence" an individual's attitude without his awareness of this "influence" process. This may be especially the case when attitude material is presented in an unambiguous fashion and when the individual has a fair prior knowledge of the attitude position. 
APPENDIX I

INSKO'S QUESTIONNAIRE 
INSKO'S QUESTIONNATRE /

1. Viewer selectivity, not pay TV, is the way to improve TV quality.

2. Pay TV firms want to "horn in" on facilities that free TV has built.

3. Pay TV would end the current "wasteland" produced on free TV.

4. A large segment of intelligent America is being virtually ignored by the producers of current free TV.

5. Pay TV would bring live Broadway plays and exclusive sports events to everyone's television set.

6. Many IV commercials are well executed and enjoyable to watch.

7. Pay TV is within the price range of most people owning sets.

8. Pay TV will bring cultural events to outlying areas which otherwise would have no opportunity to see them.

9. Pay TV would not offer much you cannot see now for free.

10. The reduction or elimination of commercials from television would hurt the American economy.

11. Since advertising either cannot, or believes it cannot, support certain high-quality programs, a ready-made audience awaits widespread pay TV.

12. No private interest, such as those who propose to operate pay TV, has the right to profit from publicly owned airwaves by charging for receiving programs over those airwaves. 


\section{APPENDIX II}

THEORETICAL ATTITUDE QUESTIONNAIRE 
THEORETICAL ATTITUDE QUESTIONNAIRE

1. In my opinion no community should be without an organized group that sponsors and promotes good music.

2. If I were a university professor and had the necessary ability, I would prefer to teach life sciences.

3. I think that modern society's single most pressing need is attunement with and appreciation of natural beauty.

4. Investigating the principles of electronics would be a meaning ful and fulfilling endeavor for me.

5. The most insightful and warm people that I know are artisticaliy and emotionally sensitive.

6. I would find a field trip to investigate the geographical features of an area very worthwhile.

7. Nothing would be quite as much fun as a truly artistic bent for photography.

8. I think that our modern industrial and scientific developments are signs of a greater degree of civilization than has ever been attained by any previous society.

9. If I could influence the educational policies of a slum school, I would first of all make provision for additional laboratory facilities.

10. If I attended an exposition, I would benefit most from going to the building where I could see the floral displays and paintings. 
11. I would find a course in the romantics exceedingly interesting.

12. The Moon landing was probably the most inspiring special on T.V. 
APPENDIX III

THEORETICAI-AESTHETIC ATTITUDE QUESTIONNAIRE 
1. In my opinion no community should be without a group that sponsors and promotes:
(1) good music
(b) vocational-technical training

2. If I were a university professor and had the necessary ability, I would prefer to teach:
(a) creative writing
(b) Iife sciences

3. I think that modern society's single most pressing need is:

(a) attunement with and appreciation of natural beauty

(b) a rigorous and logical approach to environmental problems

4. A meaning ful and fulfilling endeavor for me would be investigating the principles of:
(a) poetic imagery
(b) electronics

5. The most insightful and warm people that I know are:

(a) logical and factual

(b) artistically and emotionally sensitive

6. I would find it very worthwhile to go on a field trip to investigate:
(a) the geographical features of an area
(b) Indian art

7. Nothing would be quite as much fun as:

(a) a truly artistic bent for photography

(b) an ability to conceptualize nature in a purely numerical way 
8. I think that our modern society has attained a greater degree of civilization than any other previous society by virtue of:

(a) modem industrial and scientific developments

(b) modern architecture

9. If I could influence the educational policies of a slum school, I would first of all make provision for additional:
(a) laboratory facilities
(b) creative (artistic) facilities

10. If I attended an exposition I would benefit most from going to the buildings where I could see:
(a) floral displays and paintings
(b) a new combustion engine being displayed

11. I would find it exceedingly interesting to take a course in the:

(a) thought of the romantics

(b) physical theories of the origins of the Earth

12. Probably the most inspiring special on T.V. in the last five years was:

(a) the Moon landing

(b) Auguste Rodin: The Mystic Sculptox 


\section{APPENDIX IV}

DULANY'S AWARENESS QUESTIONNAIRE 


\section{DULANY'S AWARENESS QUESTIONNAIRE}

1. Did you notice whether or not I said anything during the experiment?

2. (a) Did you come to think it. was random or did it follow anything in particular you did? (b) What?

3. (a) Did you come to think there was or wasn't any purpose or significance to the word "Good" in this experiment? (b) What?

4. (a) Did you come to think that there was anything you were supposed to say, or not say, on each trial in order to be correct-asomething the experimenter wanted you to say or not say? (b) What? (c) Did you come to think there was or wasn't any kind of correct response? 
APPENDIX V

INSTRUCTIONS 


\section{INSTRUCTIONS}

\section{Group I (Theoretical-Aesthetic Attitude Questionnaire)}

You will be administered a questionnaire that is concermed with individuals' attitudes towards science. There are twelve statements or questions with two alternative answers. Each of the statements is typed on a card and will be presented to you in this slot (E points to the slot on the screen). I want you. to read each statement aloud and tell me which of the altermative answers best indicates your personal preference. For example, if I present you with this card (E puts a card in the slot on the screen) which reads, 'Which of the following sports do you find the most exciting to watch? (a) football (b) baseball', I want you to read the statement aloud and indicate your preference by choosing one of the two alternative answers. Please do that now."

\section{Group II (Theoretical Attitude Questionnaire)}

"You will be administered a questionnaire that is concerned with individuals' attitudes towards science. There are twelve statements or questions. Each of these statements is typed on a card and will be presented to you in this slot (E points to the slot on the screen). I want you to read each statement aloud and tell me whether you agree or whether you disagree with each of the statements. For example, if I present this card to you (E puts a card into the slot on the screen) which reads, 'I find it more exciting to watch football than any other sport'. I want you to read the statement aloud and tell me whether you agree or whether you disagree with the statement. Will you please do that now"

After $S$ gave his response, $E$ asked if there were any questions about the procedure. 
Group III (Insko's attitude questionnaire)

IYou will be administered a questionnaire that is concerned with individuals' attitudes towards pay T.V. There are twelve statements. Each of these statements is typed on a card and will be presented to you in this slot ( $E$ points to the slot on the screen). I want you to read each of these statements aloud and tell me whether you agree or whether you disagree with each statement. For example,... (same as for Group II). 
APPENDIX VI

ADDITIONAI INSTRUCTIONS 
ADDITIONAL INSTRUCTIONS

The $E$ had reason to believe, on the basis of the pilot study

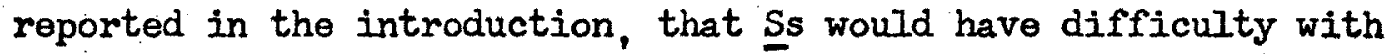
Insko's questionnaire. This apprehension proved even more troublesome than had been anticipated. The first four Ss who were administered Insko's questionnaire gave virtually all responses in favor of free T.V. The only exception to this pattern were the responses to items 6 and 10 in Insko's questionnaire which deal with commercials. This meant that $\underline{S}$ gave no reinforceable responses. The $\underline{E}$ thought that perhaps these Ss were responding on the basis of an evaluative set.-"free" is good; "pay" is bad. The $\underline{E}$ felt that the only way to introduce some response variability was to preface the administration of this questionnaire with some brief comments about the pay T.V..free T.V. controversy. The following additional instructions were given:

"The pay T.V.--free T.V. controversy was hotly debated several years ago. The present way in which T.V. is organized is on a free basis. That is, after you have purchased a television set you do not have to pay any additional money to television networks or stations. The money needed to finance T.V. is provided by advertising and commercials. If T.V. were organized on $a$ pay basis you would have to pay a certain sum of money in order to view T.V. for a period of time, say an hour, or in order to watch certain desired programs. People that favor the pay T.V. setup have argued that since individuals would provide the necessary money to finance T.V., there would be no more commercials. Since these people consider that many commercials are either boring 
or an insult to one's intelligence, they regard the elimination of commercials as a very good outcome. On the other hand, people in favor of the present system (free T.V.) argue that commercials are often entertaining and that elimination of commercials would hurt the American economy. Anyway, there are many arguments both pro and con concerning this issue."

It is interesting to note that after the present study was underway the writer read a recent study by Insko (Insko \& Cialdini, 1969) in which some of the same difficulty (response class availability) experienced by the writer was evident. Insko found that 15 of the 75 Ss that he initially sampled were not familiar with the Pay T.V. issue. Insko states that since he had not experienced this problem in previous studies, the issue must be becoming dated. 
REFERENCES 
REFERENCES

Allport, Vernon, \& Iindzey, Study of Values. Boston: Houghton Mifflin Company, 1960 .

Bandura, A. Principles of Behavior Modification. New York: Holt, Rinehart and winston, Inc., 1969.

De Nike, L. D. The temporal relationship between awareness and performance in verbal conditioning. Jourmal of Experimental Psychology, 1964, 68, 521-529.

Deese, James, \& Hulse, Stewart $H_{0}$ The Psychology of Learning. 3rd ed. New York: McGraw-Hill, Inc., 1967.

Dulany, D. E. Hypotheses and habits in verbal 'operant conditioning.' Journal of Abnormal and Social Psychology, 1961, 68, 251-263.

Eriksen, C. W. Figments, fantasies and follies: A search for the subconscious mind. In C. W. Eriksen (Ed.) Behavior and Awareness. Durham: Duke University Press, 1962. Pp. 3-26.

Farber, I. E. The things people say to themselves. American Psychologist, 1963, 18, 185-197.

Greenspoon, J. Awareness in verbal conditioning. Journal of Experimental Research in Personality, 1967, 2, 295-308.

Hildum, D. C., \& Brown, R. W. Verbal reinforcement and interviewer bias. Journal of Abnormal and Social Psychology, 1956, 53 , 108-111.

Insko, C. A., \& Butzine, K. S. Rapport, awareness, and verbal reinforcement of attitudes. Journal of Personality and Social Psychology, $1967,6,2 \overline{25-228 .}$

Insko, C. A., \& Cialdini, R. B. A test of three interpretations of attitudinal verbal reinforcement. Journal of Personality and Social Psychology, 1969, 12, 333-341.

Insko, C. A., \& Nelson, W. H. Verbal reinforcement of attitude in laboratory and nonlaboratory contexts. Joumal of Personality and Social Psychology, 1969, 37, 25-40. 